\title{
Corrigendum: Quantitative real-time imaging of glutathione
}

\author{
Xiqian Jiang, Jianwei Chen, Aleksandar Bajić, Chengwei Zhang, Xianzhou Song, Shaina L. Carroll, \\ Zhao-Lin Cai, Meiling Tang, Mingshan Xue, Ninghui Cheng, Christian P. Schaaf, Feng Li, Kevin R. MacKenzie, \\ Allan Chris M. Ferreon, Fan Xia, Meng C. Wang, Mirjana Maletić-Savatić \& Jin Wang
}

Nature Communications 8:16087 doi: 10.1038/ncomms16087 (2017); Published 13 Jul 2017; Updated 3 Oct 2017.

Previous work by Cho and Choi describing the development of a cyanoacrylamide-based fluorescence sensor for reversible detection of thiols in homogenous solutions was inadvertently omitted from the reference list of this Article. This work should have been cited in the first paragraph of the discussion, following the rationale behind the development of the Michael acceptor, as follows: 'A fluorescent sensor based on the cyanoacrylamide Michael acceptor has previously been shown to reversibly react with thiols in homogenous solutions but without any cellular applications, possibly due to the low quantum yield and poor aqueous solubility (Cho et al., 2012)'.

Cho, A. Y. \& Choi, K. A coumarin-based fluorescence sensor for the reversible detection of thiols. Chem. Lett. 41, 1611-1612 (2012).

\footnotetext{
Open Access This article is licensed under a Creative Commons Attribution 4.0 International License, which permits use, sharing, adaptation, distribution and reproduction in any medium or format, as long as you give appropriate credit to the original author(s) and the source, provide a link to the Creative Commons license, and indicate if changes were made. The images or other third party material in this article are included in the article's Creative Commons license, unless indicated otherwise in a credit line to the material. If material is not included in the article's Creative Commons license and your intended use is not permitted by statutory regulation or exceeds the permitted use, you will need to obtain permission directly from the copyright holder. To view a copy of this license, visit http://creativecommons.org/licenses/by/4.0/
}

(C) The Author(s) 2017 